\title{
Endoscopic endonasal resection of skull base meningiomas: the significance of a "cortical cuff" and brain edema compared with careful case selection and surgical experience in predicting morbidity and extent of resection
}

\author{
Osaama H. Khan, M.D., M.Sc., ${ }^{1}$ ViJay K. Anand, M.D., ${ }^{2}$ \\ ANd Theodore H. Schwartz, M.D. ${ }^{2-4}$ \\ ${ }^{1}$ Division of Neurosurgery, Toronto Western Hospital, University of Toronto, Ontario, Canada; and \\ Departments of ${ }^{2}$ Otolaryngology-Head and Neck Surgery, ${ }^{3}$ Neurological Surgery, and ${ }^{4}$ Neurology, Weill \\ Medical College of Cornell University, New York Presbyterian Hospital, New York, New York
}

\begin{abstract}
Object. This paper describes a consecutive series of skull base meningiomas resected using an endoscopic endonasal approach through various corridors at a single institution over 7 years. The impact of case selection and experience, the presence of a cortical cuff between the tumor and surrounding vessels, and brain edema on morbidity and rates of gross-total resection (GTR) were examined.

Methods. A retrospective review of a series of 46 skull base meningiomas from a prospective database was conducted. The series of cases were divided by location: olfactory groove $(\mathrm{n}=15)$, tuberculum and planum $(\mathrm{n}=20)$, sellar/cavernous $(n=9)$ and petroclival $(n=2)$. Gross-total resection was never intended in the sellar/cavernous tumors, which generally invaded the cavernous sinus. Clinical charts, volumetric imaging, and pathology were reviewed to assess the extent of resection and complications. Cases were divided based on a time point in which surgical technique and case selection improved into Group 1 (surgery prior to June 2008; $n=21$ ) and Group 2 (surgery after June $2008 ; n=25$ ) and into those with and without a cortical cuff and with and without brain edema.

Results. Improved case selection had the greatest impact on extent of resection. For the entire cohort, rates of GTR went from $38 \%$ to $76 \%$ ( $\mathrm{p}=0.02)$, and for cases in which GTR was the intent, the rates went from $63 \%$ to $84 \%$ (not significant), which was mostly driven by the planum and tuberculum meningiomas, which went from $75 \%$ to $91.7 \%$ (nonsignificant difference). The presence of a cortical cuff and brain edema had no impact on outcomes. There were 3 CSF leaks (6.5\%) but all were in Group 1. Hence, CSF leak improved from $14.2 \%$ to $0 \%$ with surgical experience. Lessons learned for optimal case selection are discussed.

Conclusions. Surgical outcome for endonasal endoscopic resection of skull base meningiomas depends mostly on careful case selection and surgical experience. Imaging criteria such as the presence of a cortical cuff or brain edema are less important.
\end{abstract}

(http://thejns.org/doi/abs/10.3171/2014.7.FOCUS14321)

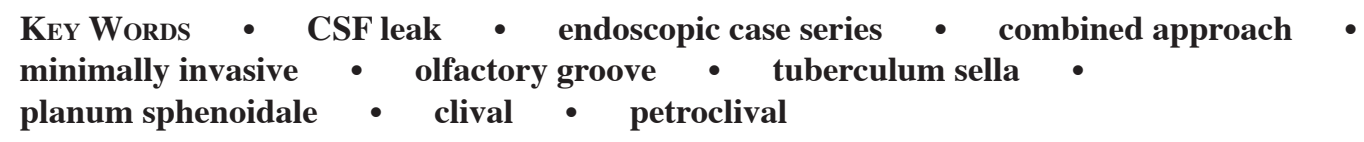

$\mathrm{M}$ ENINGIOMAS of the anterior skull base have been traditionally approached through transcranial approaches or, when paranasal regions are involved, combined craniofacial resections. . $14,22,27,28,40,46^{2}$ While these approaches offer wide exposure and working space, brain retraction, postoperative seizures, neurovascular manipulation, sinus obliteration, wound healing, and cosmesis can be significant issues. With the evolution of endoscope-assisted surgery, endonasal endoscopic approaches through the ethmoids, fovea ethmoidalis, crib-

\footnotetext{
Abbreviations used in this paper: $\mathrm{DI}=$ diabetes insipidus; GTR = gross-total resection; SPGR = spoiled gradient recalled echo; STR = subtotal resection.
}

riform plate, clivus, and planum sphenoidale have been developed as useful alternatives. $5,6,13,15,19,20,24,33,45,49$

However, the use of extended endonasal endoscopic approaches in the surgical treatment of skull base meningiomas is perhaps the most controversial application of this technique. The criticisms have focused on the following key issues. First, the approach is through an infected field, resulting in a potentially higher risk of intracranial infection. Second, the risk of CSF leak has been high in many of the reported series. Third, the exposure is too limited to remove the dural tail and obtain a complete resection. Fourth, the corridor is too narrow to permit microsurgical dissection of blood vessels attached to the tumor capsule, requiring a "cortical cuff" to be present 
between the tumor and the vessels. ${ }^{26,52}$ Fifth, any evidence of edema in the adjacent brain indicates possible brain invasion requiring complex brain dissection and hemostasis techniques not possible with endonasal surgery. ${ }^{52}$ While each of these points has merit, they are primarily derived from results achieved in the early years of endonasal surgery before the development of a variety of technical advances that have made these approaches both more effective and safer. Likewise, recommendations regarding appropriate case selection were not clear given the lack of experience and consensus within the endonasal surgical community.

As our center gained more experience applying endonasal surgery to meningiomas, our thinking evolved regarding the role and applicability of these approaches to a variety of meningiomas and our selection of cases matured. In this paper we review a relatively large series of meningiomas in which endonasal skull base approaches were used either alone or in combination with a craniotomy, and demonstrate not only the evolution of our results but also the lessons we have learned that help us select appropriate cases for surgery. Our purpose is not to convince the reader that endonasal endoscopy should replace craniotomy, but rather demonstrate how this technique can be used to complement transcranial surgery. In particular, we examine the relative role of case selection and technique development compared with other previously identified factors, such as the presence or absence of a cortical cuff and brain edema, in determining outcome such as extent of resection and morbidity.

\section{Methods}

\section{Study Population}

Patients were drawn from a prospective database of a consecutive series of patients who underwent endonasal endoscopic surgery between March 2005 to April 2013. The surgeries were performed by the senior authors, an otolaryngologist (V.K.A.) and a neurosurgeon (T.H.S.), and only histologically confirmed meningiomas were identified. Institutional Review Board approval at Weill Cornell Medical College was obtained for this study. Patients were divided into 2 historical groups. Group 1 consisted of patients who underwent operations before June 2008, while Group 2 underwent surgery after June 2008. Group 1 represented cases early in our experience during our "learning curve." We chose these data specifically because in June 2008 we adopted the nasoseptal flap for closure and routinely used the "gasket-seal" and a lumbar drain (described below; Table 1).

Data entered prospectively into our database included information on the approach, presence of an intraoperative CSF leak, closure materials, and use of lumbar drainage. Other end points discussed below were acquired retrospectively from chart and radiology review. Some of these patients were included in earlier studies but without investigation of the presence of a cortical cuff or brain edema. ${ }^{2,33,43}$

\section{Clinical and Radiological Evaluation}

Medical records were retrospectively reviewed for medical history, physical examination results, neurological signs, visual function, patient imaging, operative reports, surgical technique, operative results, patient outcomes, and follow-up office visits. Complete endocrinological assessments of all pituitary axes were performed pre- and postoperatively. Prior to surgery all patients underwent stereotactic Gd-enhanced T1-weighted and FLAIR MRI for image guidance. Following surgery, all patients had an MRI scan with contrast, including a spoiled gradient recalled echo (SPGR) 1-mm coronal scan at both 2 days and 3 months. Extent of resection was determined by a neuroradiologist performing volumetric calculations comparing preoperative SPGR images acquired for neuronavigation with postoperative images, and classified as gross-total resection (GTR), near-total resection $(\geq 95 \%$ ), or subtotal resection (STR; $\leq 95 \%$ ). The radiologist also determined preoperatively if there was edema in the brain, based on examination of the FLAIR images, and whether there was a "cortical cuff," i.e., brain juxtaposed between the tumor and adjacent cortical vessels. The radiologists were not blinded to the extent of resection when these determinations were made, but they were not aware that these data points were going to be correlated with outcome.

\section{Operative Approach}

The details of the surgical approaches have been described previously. ${ }^{2,32-34,43}$ However, there are certain specifics that are worth discussing with respect to patient selection and technique that inform our results. Meningiomas are given 3 antibiotics preoperatively: vancomycin, ceftriaxone, and metronidazole. Intraoperative cranial nerve or somatosensory monitoring was used intermittently depending on the location of the pathology and the patient's preoperative examination. A lumbar drain was placed at the start of the operation if a large dural opening was anticipated, which is generally the case for meningioma surgery. Otherwise, a lumbar puncture was performed to administer $0.25 \mathrm{ml}$ of $10 \%$ fluorescein (AKFluor, Akorn) with $10 \mathrm{ml}$ of CSF to help visualize CSF leaks and to ensure there was no leak after reconstruction of the skull base. ${ }^{23,44,47}$ Glucocorticoids and antihistamines were given to prevent a hypothetical allergic reaction to fluorescein. Once in rigid head fixation, patients were registered with the frameless stereotactic equipment to preoperatively acquire MRI and/or CT angiography. Our closure technique has evolved over time, with some overlap between the periods they were used. ${ }^{37}$ We started by using intracranial fat with an overlay of fascia lata and then artificial tissue sealant, either Tisseel (Baxter) in the earlier years or Duraseal (Covidien) starting in 2006. This closure evolved into the "gasket seal" closure, which consisted of an overlay of fascia lata buttressed with a countersunk piece of Medpore (Porex). ${ }^{18,35}$ After June 2008, we adopted the nasoseptal flap ${ }^{21}$ in addition to the gasket seal $^{18,35}$ for floor reconstruction..$^{39,41}$ If a lumbar drain is placed, it is generally left in place for only 24 hours at a rate of $5 \mathrm{ml} /$ hour and removed on postoperative Day 1 at night so the patients can get out of bed on postoperative Day 2. 


\section{Endoscopic resection of skull base meningiomas}

TABLE 1: Significance of surgeon experience, cortical cuff, and brain edema

\begin{tabular}{|c|c|c|c|c|c|c|}
\hline \multirow[b]{2}{*}{ Variable } & \multicolumn{2}{|c|}{ Entire Cohort (\%) } & \multicolumn{2}{|c|}{ Olfactory Groove (\%) } & \multicolumn{2}{|c|}{ Planum/Tuberculum (\%) } \\
\hline & GTR & Complications & GTR & Complications & GTR & Complications \\
\hline Group 1 & 38 & 29 & 75 & 50 & 75 & 37.5 \\
\hline Group 2 & $76^{*}$ & 25 & 73 & 27 & 91.7 & 8.3 \\
\hline cortical cuff & 10 & 2.9 & 100 & 33 & 0 & 0 \\
\hline no cortical cuff & 53.3 & 11.4 & 66.7 & 33 & 85 & 15 \\
\hline brain edema & 40.9 & 2.9 & 75 & 30 & 100 & 12.5 \\
\hline no brain edema & 25 & 8.8 & 66.7 & 30 & 75 & 16.7 \\
\hline
\end{tabular}

\section{Statistical Analysis}

Student t-tests, chi-square, and Fisher exact tests were used to identify significance between groups. A p value $>$ 0.05 was not considered significant. Patients were also divided into those with and without a cortical cuff (defined as brain tissue separating the tumor capsule from vessels), and those with and without brain edema, for statistical purposes (Table 1).

\section{Results}

\section{Olfactory Groove Meningiomas}

Our thought process on surgery for olfactory groove meningiomas evolved over time. In our early experience, we attempted to use the endonasal approach alone for appropriate tumors, namely those that did not extend laterally more than $1 \mathrm{~cm}$ beyond a vertical extension of the lamina papyracea, regardless of the anterior-posterior extent. The ability to remove the entire cribriform plate early in the operation would devascularize the tumor and decrease recurrence rates from invaded bone, and also decrease brain retraction. However, we found that those meningiomas whose anterior extent was in contact with the back wall of the frontal sinus created unique challenges. First, the angle of approach rendered removal of the front of the tumor difficult, and closing a defect in the anterior fossa that extended to the back of the frontal sinus was challenging. However, our center did not use a Lothrop or Draf III surgical approach in this approach, which may have biased our impression of the resulting exposure and should be taken into account. The nasoseptal flaps often do not reach this far anteriorly and there is no ledge upon which to rest an inlay graft. Another consideration was olfaction. The endonasal approach uniformly results in a loss of olfaction when the cribriform plate is resected. Thus, for smaller tumors in which there was not only good preoperative olfaction but the possibility of preservation of olfaction postoperatively, a transcranial approach was less morbid, particularly a supraciliary "eyebrow" incision with endoscope assistance, which we used routinely. For this reason, after 2008 we began using the endonasal approach selectively, depending on the specific anatomy of the tumor, and often combined the endonasal approach with a craniotomy depending on the anatomy of the tumor and the anticipated defect in the skull base. In this series, however, we are only presenting those cases in which an endonasal endoscopic approach was used either by itself or in combination with a craniotomy. In Fig. 1 we present 4 cases, 2 of which we consider appropriate for purely endonasal resection and 2 of which we used either a combined cranionasal surgery (i.e., an endonasal endoscopic as well as a transcranial approach) or an eyebrow approach to preserve olfaction. This last case is not included in this surgical series but is useful as a comparison for surgical selection criteria.

Clinical Presentation and Radiological Findings. There were 15 patients who underwent 16 endoscopic approaches for olfactory groove meningiomas, including 4 patients in Group 1 and 11 patients in Group 2. One patient underwent a staged procedure consisting of a biopsy followed by surgical removal. In Group 1 all surgeries were uniquely endoscopic. and 4 patients in Group 2 (36\%) underwent an endoscopic approach combined with a craniotomy in either a staged or combined fashion. Mean age at surgery was 59.7 years (range 42-77 years). There were 4 males (26.7\%) and 11 females $(73.3 \%)$. The majority of patients presented with multiple complaints, with 5 patients reporting visual disturbance (33\%), 5 with headaches (33\%), 4 with personality changes $(26.7 \%)$, and 1 with facial pain $(6.7 \%)$. There were no endocrine abnormalities. In Group 1,1 patient underwent a previous surgery 30 years ago. In Group 2, 4 patients had previously undergone a remote craniotomy for tumor removal. In Group 2, 1 patient had prior fractionated stereotactic radiosurgery and 1 had Gamma Knife surgery.

Average tumor volume was $44.4 \mathrm{~cm}^{3}$ (range 13.5-90.3 $\left.\mathrm{cm}^{3}\right)$ in Group 1 and $28.8 \mathrm{~cm}^{3}$ (range $\left.1.95-130.1 \mathrm{~cm}^{3}\right)$ in Group $2(\mathrm{p}=0.47)$. Brain edema was present in 4 patients $(100 \%)$ in Group 1 and in 6 patients (54.6\%) in Group 2 (p $=0.23$, nonsignificant). Tumor was juxtaposed to the optic apparatus in 2 cases (50\%) in Group 1 and 6 cases (55\%) in Group 2 (nonsignificant difference). No patient in Group 1 $(0 \%)$ had a cortical cuff, and in Group 2,3 patients $(27.3 \%)$ had a cortical cuff (nonsignificant difference).

Operative Approach and Closure. All cases in both Group 1 and Group 2 underwent a transethmoidal transcribriform approach, but the transsphenoidal transplanum approach was also used for larger tumors that extended back above the planum sphenoidale, as in 1 case in Group 1 and in 7 cases in Group $2(p=0.28)$. The endoscope was 

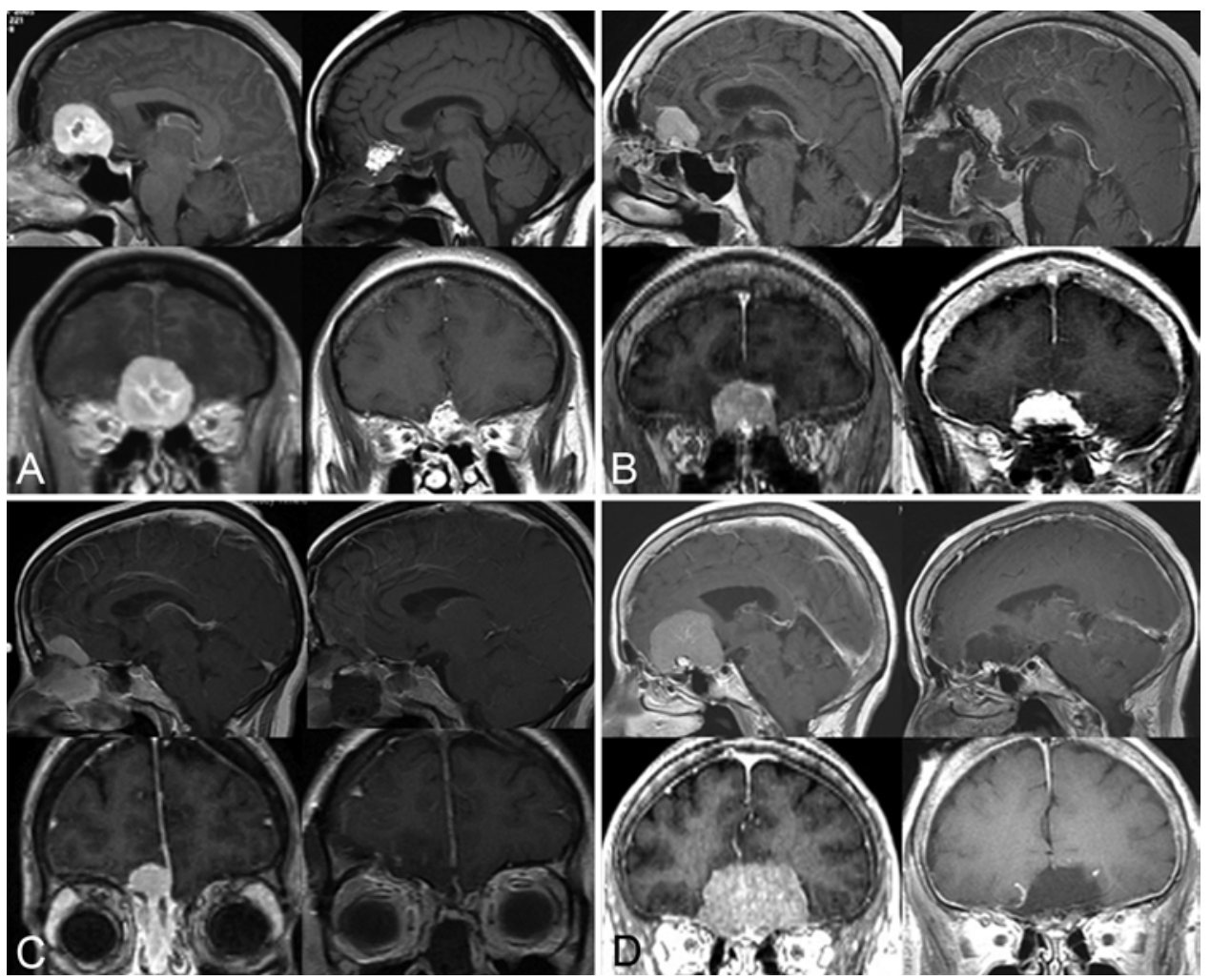

FIG. 1. Sagittal and coronal Gd-enhanced MR images of olfactory groove meningiomas (in each panel, preoperative images on the left, postoperative on the right). A: A purely endonasal case in which GTR was achieved. The fat graft can be noted in the surgical cavity on postoperative images on the right. However, olfaction was lost, and it is unclear if it could have been saved using a transcranial approach. B: Another case involving endonasal removal. The fat graft can be observed in the surgical cavity. Olfaction was lost, but likely could have been preserved if a transcranial approach had been used. C: Meningioma that extended up toward the back wall of the frontal sinus and had an intracranial and intranasal component. This tumor was removed using a combined eyebrow and endonasal, above and below approach. D: Although this tumor could be removed endonasally, we elected to perform this surgery through an eyebrow approach because the skull base closure would have been challenging given the anterior extent off the tumor and the fact that the patient had good olfaction prior to surgery. We were able to preserve olfaction. The limitation of the eyebrow approach is the residual hyperostotic bone at the base, likely infiltrated with tumor that may require radiosurgery at some point.

the sole means of resection in all 4 cases (100\%) in Group 1, whereas in Group 2, 7 cases (64\%) were purely endoscopic. Reconstruction of the skull base defect in Group 1 involved a turbinate flap in 1 case and fat with fascia lata in 3 cases. The nasoseptal flap with a gasket seal was used in all cases in Group 2. An intraoperative lumbar drain was used in all cases in Group 1 and in 9 cases in Group 2.

Surgical and Clinical Outcome. Gross-total resection was achieved in 3 patients (75\%) in Group 1 and 8 patients $(73 \%)$ in Group 2 ( $\mathrm{p}=0.93$, nonsignificant). For the purely endoscopic cases in Group 2, the GTR rate was 86\%. GTR rates were $100 \%$ in patients with a cortical cuff and $66.7 \%$ in patients without a cortical cuff ( $\mathrm{p}=0.52$, nonsignificant). GTR rates were $75 \%$ in patients with brain edema and $66.7 \%$ in patients without brain edema $(\mathrm{p}=1$, nonsignificant). Residual volume was $24.4 \mathrm{~cm}^{3}$ in Group 1 and $8.7 \mathrm{~cm}^{3}$ in Group 2.

The total permanent complication rate was 33\%, which included 50\% in Group 1 and 27\% in Group 2 (p $=0.56)$. Complication rates were $33 \%$ in patients with a cortical cuff, $33 \%$ in patients without a cortical cuff (nonsignificant), $30 \%$ in patients with brain edema, and $30 \%$ in patients without brain edema (nonsignificant differences). There were no postoperative endocrinopathies in Group 1 , whereas 1 patient in Group 2 had transient postoperative diabetes insipidus (DI) and another had transient syndrome of inappropriate antidiuretic hormone. There were no visual complaints preoperatively in Group 1, with no subsequent complaints postoperatively. Four patients in Group 2 experienced improvement of vision postoperatively $(80 \%)$, and 1 patient had no improvement $(20 \%)$. In Group 1 there was $1 \mathrm{CSF}$ leak (25\%) that required a craniotomy for repair. There were no CSF leaks ( $0 \%$ in Group 2. In Group 1 there was 1 patient who had a postoperative posterior sellar collection believed to be infection that required endoscopic exploration, with final cultures and pathology negative for infection, consistent with a resolving hematoma. In Group 2 there were 2 postoperative infections. The first patient developed nasal discharge and vomiting that required an endoscopic washout without floor reconstruction and was discharged with 6 weeks of intravenous antibiotics. Another patient developed a postoperative abscess of the back wall of the sphenoid sinus that required craniotomy for appropriate washout. In Group 2 there was 1 patient who developed a postop- 
erative deep venous thrombosis and pulmonary embolus treated with anticoagulation, and subsequently developed an intracerebral and subdural hemorrhage on postoperative Day 9 that required a craniotomy for evacuation.

Pathology revealed WHO Grade I meningioma in all patients in both groups, except 1 patient in Group 2 who had a WHO Grade III meningioma. Two patients in Group 2 were referred for radiation treatment for a residual tumor. The average follow-up in Group 1 was 85.5 months (range 65-103 months), and 27 months (range 3-53 months) for Group 2. There was 1 recurrence after 4 years of followup from a patient in Group 1 (25\%) who required a craniotomy for resection.

\section{Tuberculum and Planum Meningiomas}

As opposed to olfactory groove meningiomas, our philosophy on planum and tuberculum meningiomas is somewhat different. We offer endonasal surgery for all planum and tuberculum meningiomas that do not extend laterally beyond the internal carotid artery bifurcation or laterally beyond the optic nerves. Contraindications include extension to the anterior clinoid processes and clear encasement of the internal carotid artery, anterior cerebral artery complex, or optic nerves. However, even these factors are not absolute contraindications if the goals of surgery are debulking and not GTR. In most situations, however, the goals of surgery are GTR for planum and tuberculum meningiomas. Tumor in the medial optic canals is not a contraindication because the optic canals can be opened endonasally. ${ }^{3}$ Figure 2 shows examples of 4 cases, with descriptions of some of the key considerations in choosing appropriate cases.

Clinical Presentation and Radiological Findings. There were 20 patients in this cohort (tuberculum and planum meningiomas), 8 in Group 1 and 12 in Group 2. In this series all patients were selected to undergo a purely endonasal expanded endoscopic approach. No staged or transcranial approaches were required. The mean age at surgery was 56.5 years (range 31-81 years). There were 6 males $(30 \%)$ and 14 females (70\%). Two patients had undergone transcranial surgery previously and 1 had prior transsphenoidal surgery with STR, which were all performed at outside institutions. No patients had any prior radiation treatment. Preoperative symptoms included visual impairment only (50\%), visual impairment and headaches (30\%), visual impairment and panhypopituitarism (5\%), headaches only (5\%), and endocrine abnormalities only (5\%).

Average tumor volume in Group 1 was $11.92 \mathrm{~cm}^{3}$, and in Group 2 was $12.02 \mathrm{~cm}^{3}$ (nonsignificant difference). Seven $(35 \%)$ of 20 meningiomas showed peritumoral brain edema. Nine meningiomas $(45 \%)$ originated from the tuberculum sellae, 7 (35\%) from the planum sphenoidale, $3(15 \%)$ from both the tuberculum sellae and the planum sphenoidale, and $1(5 \%)$ that was within the third ventricle. The tumor was juxtaposed to the optic apparatus in all 20 patients. In no patient was a cortical cuff identified, except for the tumor within the third ventricle.

Operative Approach and Closure. The surgical approach for all cases was transsphenoidal transtuberculum transplanum, with the addition of the transethmoidal tran- scribriform approach in 2 cases in which the tumor extended more anteriorly than just the planum sphenoidale. Closure was conducted with a variety of materials and techniques in Group 1, including inlays of fat and fascia lata, onlays of fat and fascia lata, and intermittent buttressing with vomer and MEDPOR (Stryker) in select cases. However, in Group 2, all patients had a gasket-seal closure covered with a nasoseptal flap. Sixteen patients had an intraoperative lumbar drain placed prior to surgery, which was continued postoperatively for 24 hours at $5 \mathrm{ml} /$ hour. Lumbar drains were placed in 50\% in Group 1 and 100\% in Group 2.

Surgical and Clinical Outcome. Gross-total resection was achieved in 17 patients $(85 \%)$ in this group. In the remaining patients with STR, the extent of resection was $66.6 \%$, with an average residual volume of $0.63 \mathrm{~cm}^{3}$. For Group 1, GTR was 75\%, and for Group 2, GTR was $91.7 \%$. Although this was a dramatic increase in GTR rate, the difference was not statistically significant $(p=0.54)$. The reason for STR was a tumor extending lateral to the anterior clinoid process ( 2 cases) and tumor attached to $\mathrm{A}_{2}$ branches ( 2 cases). The latter cases occurred in the early part of our series when our bone openings were not as large; we used pistol-gripped instead of bayonetted instruments and we were less comfortable operating with a $30^{\circ}$ endoscope. There was no significant relationship between tumor volume and GTR $(\mathrm{p}=0.526)$. GTR rates were $0 \%$ in patients with a cortical cuff and $85 \%$ in patients without a cortical cuff (nonsignificant difference). GTR rates were $100 \%$ in patients with a brain edema and $75 \%$ in patients without brain edema ( $\mathrm{p}=0.24$, nonsignificant).

The clinical symptoms described above improved in most of the cases. Among the 17 patients with preoperative visual complaints, $14(82.4 \%)$ had improvement of vision, while $3(17.6 \%)$ had no improvement. No patients experienced deterioration of vision. Visual improvement was $87.5 \%$ for Group 1 and $80 \%$ for Group 2. Although visual improvement was better in Group 1, the difference was not statistically significant $(p=1)$. Headaches resolved in all cases. The endocrine abnormalities in 2 patients remained unchanged.

The total permanent complication rate was $15 \%$, which was $0 \%$ in patients with a cortical cuff, $15 \%$ in patients without a cortical cuff (nonsignificant difference), $12.5 \%$ in patient with brain edema, and $16.7 \%$ in patients without brain edema (nonsignificant differences). A CSF leak occurred in 2 patients in Group 1 (25\%). One patient was treated with a lumbar drain while the other required an endonasal reexploration as well as a craniotomy. This same patient, who was operated upon at the beginning of our series (Group 1), had a history of sarcoidosis, renal failure, and steroid dependence, and suffered multiple complications resulting in sepsis and death. Our rate of transient complications in Group 1 was $37.5 \%$ (2 patients with CSF leak, 1 with DI) and in Group 2 was $8.3 \%$ (1 patient with DI). The CSF leak rate was $25 \%$ in Group 1 and $0 \%$ in Group 2. The differences in complication rate $(\mathrm{p}=1)$ and CSF leak rate $(\mathrm{p}=0.15)$ between Groups 1 and 2 were not statistically significant (Table 1 ). The postoperative histopathological analysis of the tumors revealed 

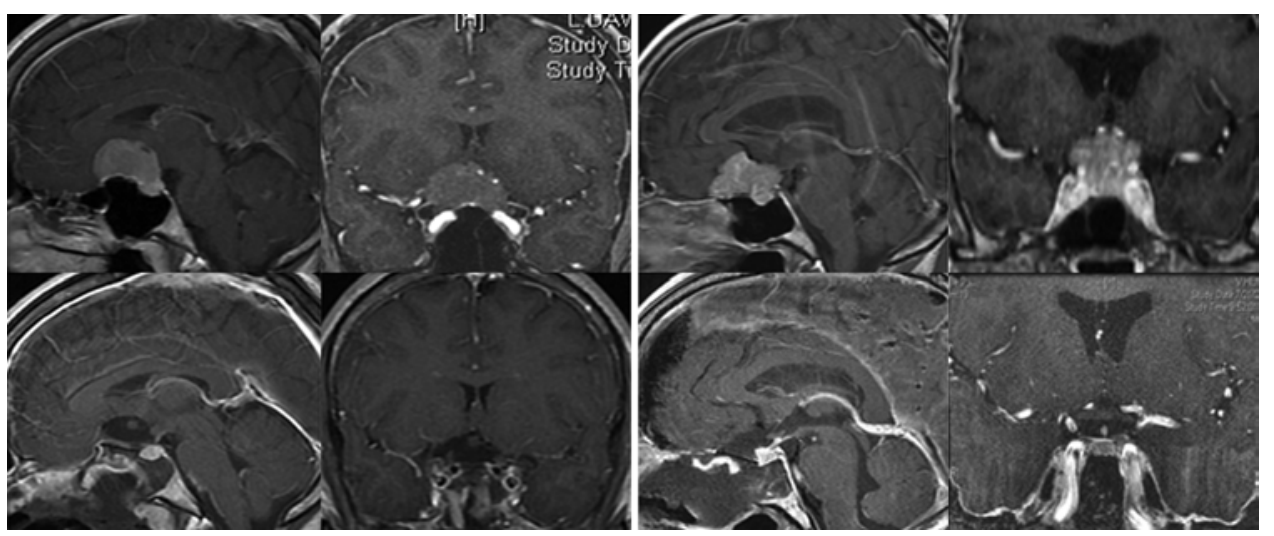

FIG. 2. Sagittal and coronal Gd-enhanced MR images of planum and tuberculum meningiomas showing GTR of planum sphenoidale meningiomas. Note that there is no cortical cuff in either of these patients.

that all meningiomas included in this study were WHO Grade I.

Follow-Up and Recurrence. Follow-up ranged from 5 to 96 months (average 51.5 months). There were 2 tumor recurrences. One patient has received postoperative 3D confocal external beam radiation for residual tumor surrounding the anterior circulation. One patient with residual tumor superior and lateral to the internal carotid artery and optic nerve has undergone a craniotomy to remove her recurrent tumor.

\section{Sellar/Cavernous Sinus Meningiomas}

Philosophically, in our opinion patients with cavernous sinus meningiomas are not candidates for GTR. However, biopsy may be useful to ensure the diagnosis of meningioma, and an endonasal approach allows this procedure to be conducted in a minimally invasive manner. Likewise, patients with tumors in the sella or adjacent to the optic nerves and chiasm may require removal of the tumor and placement of a fat graft to mobilize the chiasm, optic nerve, and pituitary gland away from the residual cavernous sinus tumor in preparation for radiosurgery, to reduce the risk of post-stereotactic radiosurgery hypopituitarism or radiation-induced optic neuropathy. The utility of this type of pituitary transposition or "hypophysopexy" has been described by other authors., ${ }^{9,36,48}$ Figure 3 demonstrates examples of sellar and cavernous meningiomas suitable for endonasal surgery.

Clinical Presentation and Radiological Findings. There were 9 patients with sellar/cavernous sinus meningiomas, 7 in Group 1 and 2 in Group 2. The mean age at surgery was 49.8 years (range 23-58 years). There was 1 male and 6 females in Group 1, and 2 females in Group 2. All patients $(100 \%)$ in Group 1 had visual disturbances, whereas Group 2 had 1 patient with amenorrhea and the other with headache. Group 1 had 1 patient with endocrinopathy with hypothyroidism, and all in Group 2 had amenorrhea. All patients in Group 1 had undergone a craniotomy before the endoscopic approach, including 2 at an outside facility. No patient had previously undergone cranial irradiation.

The average tumor volume was $30.4 \mathrm{~cm}^{3}$ (range 1.36 $107.27 \mathrm{~cm}^{3}$ ) and $18.91 \mathrm{~cm}^{3}$ (range $1.36-36.46 \mathrm{~cm}^{3}$ ) in
Groups 1 and 2, respectively. Brain edema was present in $85 \%$ of Group 1 and $0 \%$ of Group 2. The tumor involved the optic apparatus in all patients in Group 1, and in only 1 patient in Group 2. There was no cortical cuff identified in either Group.

Operative Approach and Closure. The surgical approach for Group 1 was via transsphenoidal, transsellar, and transplanum, with 2 pituitary transpositions for adjuvant postoperative radiotherapy. For Group 2, the approach was transsphenoidal transsellar in both cases, with pituitary transposition in 1 patient. Reconstruction of the skull base was achieved with a nasoseptal flap in all cases in Group 2. A combined open and endoscopic approach was used in 4 cases (57\%) in Group 1 and 0 cases (0\%) in Group 2. Only 3 patients (43\%) had an intraoperative lumbar drain placed in Group 1, and none in Group 2.

Surgical and Clinical Outcome. GTR was never the goal in this cohort but was achieved in 1 patient. Average residual tumor volume in Group 1 was $30.4 \mathrm{~cm}^{3}$ (range $0.78-56.42 \mathrm{~mm}^{3}$ ), and $18.9 \mathrm{~cm}^{3}$ (range $1.36-36.5 \mathrm{~cm}^{3}$ ) in Group 2. In $6(86 \%)$ of the patients in Group 1, residual volume was located in the cavernous sinus. No cortical cuff was identified in any of the 9 cases. In Group 1, 6 cases $(86 \%)$ had brain edema. No brain edema was identified in Group 2.

The total permanent complication rate was $22 \%$, including $33 \%$ in patients with brain edema and $0 \%$ in patients without brain edema (nonsignificant difference). There were no CSF leaks (0\%). One patient in Group 1 had transient DI. One patient who underwent a combined approach required a ventriculoperitoneal shunt for hydrocephalus in the postoperative period of the same hospital admission, and another patient in the same group had meningitis after the craniotomy, which required antibiotic treatment. In Group 1, 5 patients experienced visual improvement $(71.4 \%) ; 1$ had no change (14\%), while another had visual deterioration (14\%). In Group 1, pathology was WHO Grade I in 4 cases and WHO Grade II in 3 cases, whereas in Group 2 pathology was Grade I in all cases. Four patients in Group 1 received postoperative radiation therapy, as did both patients in Group 2. The average follow-up duration was 20.6 months (range 6-34 months) in Group 1 and 7.5 months (range 6-9 months) in Group 2. 


\section{Endoscopic resection of skull base meningiomas}

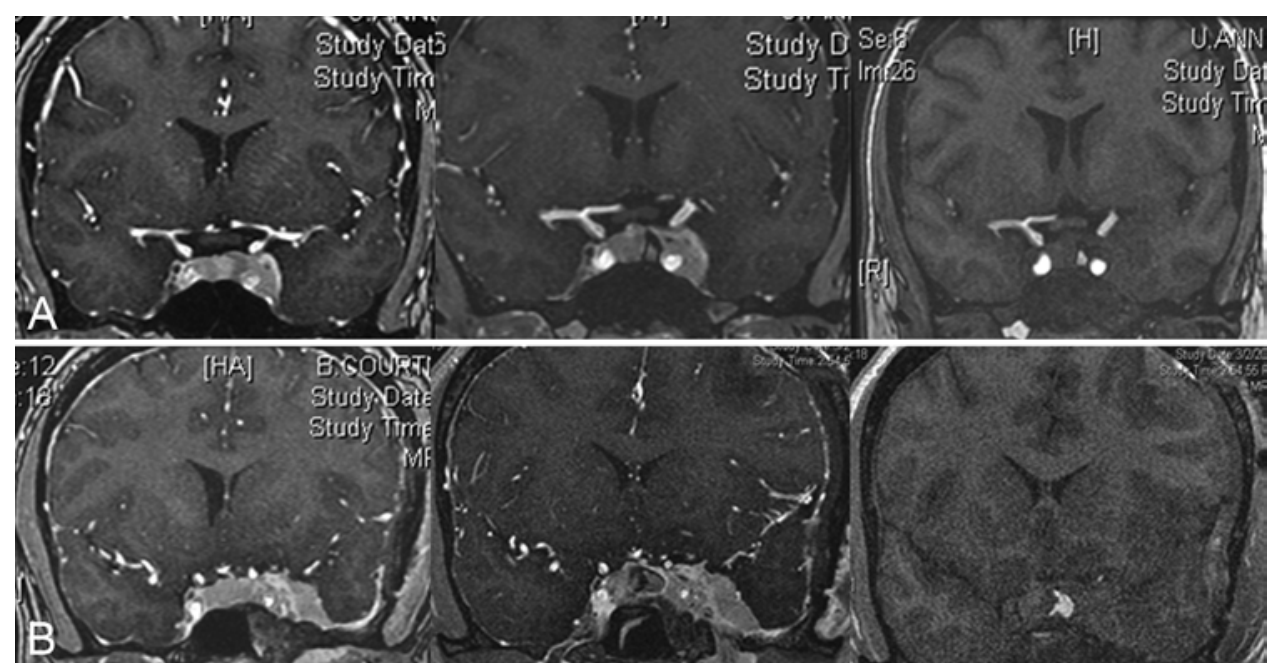

FIG. 3. Coronal MR images of sellar and cavernous meningiomas in 2 patients. Preoperative contrast-enhanced (left column), postoperative contrast-enhanced (center column), and postoperative nonenhanced (right column) images show pituitary transposition with a fat graft to protect the pituitary gland from radiosurgery.

\section{Clival and Petroclival Meningiomas}

Although we offered endonasal surgery to 2 patients with petroclival meningiomas at the beginning of our series, our experience with these tumors in which GTR was the goal of surgery was not as encouraging as with other types of meningiomas. Therefore, our experience in this area is limited. Although brainstem decompression is certainly feasible, resection of tumor lateral to the petrous apex is quite challenging, and resection of tumor adherent to the basilar artery and its perforators and brainstem is also difficult from a ventral angle. Likewise, if the dural attachment extends past the medial wall of the vertical carotid artery, there is likely to be residual tumor. Although the endonasal approach clearly offers improved visualization of the tumor arising from the midline clivus over any transcranial approach, if the goal is complete tumor removal, we found a transcranial approach to be more appropriate to reach all components of the tumor. However, a combined approach is also reasonable whereby the lateral components are removed transcranially and ventral components removed endonasally.

Clinical Presentation and Radiological Findings. There were 2 female patients in this cohort, both in Group 1. The mean age at surgery was 70.5 years (range 70-71 years). One case was uniquely endoscopic and brainstem decompression was the goal, and the other was combined with a craniotomy to reach the lateral part of the tumor to achieve GTR. Presentation for both patients was headache, with 1 also having visual disturbance. No endocrine dysfunction was identified. Average tumor volume was $6.47 \mathrm{~cm}^{3}$ (range $2.94-10.0 \mathrm{~cm}^{3}$ ). Brain edema was present in 1 patient. No cortical cuff was identified in either case.

Operative Approach and Closure. Surgical approach was transsphenoidal transclival in the patient with a decompression, with pituitary transposition in the second patient who also underwent a craniotomy. Reconstruction of the skull base was not conducted using a nasoseptal flap, but with a gasket seal with fascia lata, fat, vomer, Gelfoam (Pfizer), and Floseal (Baxter). A lumbar drain was placed in the operating theater for the patient with pituitary transposition, but neither patient required postoperative insertion of a lumbar drain.

Surgical and Clinical Outcome. Gross-total resection was not achieved in either of these cases. Average residual tumor volume was $1.07 \mathrm{~cm}^{3}$ (range $1-1.14 \mathrm{~cm}^{3}$ ). Subtotal resection achieved a $75.6 \%$ reduction in volume. The complication rate was $50 \%$. There were no CSF leaks. There were no postoperative endocrinopathies. One patient had a brainstem stroke resulting in hemiparesis and unilateral hearing loss. Pathology revealed WHO Grade I meningioma in both patients. One patient was referred for postoperative radiosurgery. Average follow-up was 42.5 months (range 15-70 months).

\section{Significance of Case Selection and Technical Improvements, Cortical Cuff, and Brain Edema on GTR, Complications, and CSF Leak for the Entire Cohort}

For the entire cohort $(n=46)$ the rate of GTR was $63 \%$, and for the cases in which GTR was the intent of surgery $(n=37)$, the rate was $76 \%$. Rates of GTR were $38 \%$ in Group $1(\mathrm{n}=21)$ and $76 \%$ in Group $2(\mathrm{n}=25 ; \mathrm{p}=$ 0.02). If we exclude the cases in which GTR was not the intention of surgery, the GTR rates were 64\% in Group $1(\mathrm{n}=14)$ and 84\% in Group $2(\mathrm{n}=23$; nonsignificant difference). The rate of complications was $29 \%$ in Group 1 and $25 \%$ in Group 2 ( $\mathrm{p}=0.73$, nonsignificant). There were 3 CSF leaks (4.6\%), all in Group 1, so the rate decreased from $14.3 \%$ in Group 1 to $0 \%$ in Group 2. Rates of GTR were $10 \%$ and $53.3 \%$ in patients with and without a cortical cuff, respectively (nonsignificant difference), and $40.9 \%$ and $25 \%$ in patients with and without brain edema, respectively (nonsignificant difference). The rates of complications were $2.9 \%$ and $11.4 \%$ in patients with and without a cortical cuff, respectively (nonsignificant difference), and $2.9 \%$ and $8.8 \%$ in patients with and without brain edema, respectively (nonsignificant difference). 
If we exclude patients who also underwent a craniotomy and only examine those who underwent a purely endoscopic approach $(\mathrm{n}=35)$, the rates of GTR were $5.7 \%$ and $65.7 \%$ in patients with and without a cortical cuff, respectively (nonsignificant difference), and $42.9 \%$ and $28.6 \%$ in patients with and without brain edema, respectively (nonsignificant difference). The rates of complications were $2.9 \%$ and $26.5 \%$ in patients with and without a cortical cuff, respectively (nonsignificant difference), and $20 \%$ and $8.6 \%$ in patients with and without brain edema, respectively (nonsignificant difference).

\section{Discussion}

Anterior skull base meningiomas comprise approximately $10 \%$ of meningiomas. ${ }^{8,11,51}$ Although classically approached via a craniotomy, over the last 2 decades the endonasal endoscopic approach has grown in popularity, arising from a collaboration with otolaryngologists, advances in technology, and evolving techniques in cranial fossa floor reconstruction. Although the extended transsphenoidal approach for anterior skull base meningiomas was originally conceived by Weiss, ${ }^{50}$ Mason et al., ${ }^{38}$ Kitano and Taneda, ${ }^{30}$ Kaptain et al. ${ }^{25}$ and Couldwell et al. ${ }^{10}$ using a microscope, several groups have now reported results of endonasal, transsphenoidal, purely endoscopic meningioma surgeries. ${ }^{7,12,15,16,19,29,42,49}$ To date, limited large series have been reported that combine meningiomas in various locations and also discuss principals of case selection and factors correlating with results. Moreover, several recent papers have tried to outline factors that correlate with higher morbidity to assist the clinician with patient selection. In this paper we examined 2 of these factors, namely the absence of a cortical cuff indicating the proximity of small perforators to the tumor capsule, ${ }^{26,52}$ and the presence of brain edema as an indication of brain invasion. ${ }^{52}$ Our results in this large series of meningiomas indicate that these factors may not be as important as careful case selection and technical skills that are acquired over time.

In fact, a cortical cuff is almost never present in most anterior skull base meningiomas that are large enough to require surgery because the anterior cerebral arteries lay so close to the back of most of these tumors. Requiring a cortical cuff would eliminate almost all tumors from consideration. In our entire series, we only found a cortical cuff in 3 cases, all within the olfactory groove meningioma cohort. Likewise, brain edema is frequently encountered in these cases and the ability to perform careful bimanual surgery is adequate to manage these cases without a significant increase in morbidity. Hence, these criteria should not be considered as contraindications for surgery in experienced hands.

With experience, of course, also comes careful case selection. For this reason, we presented several of the more critical lessons we have learned in choosing meningiomas for surgery. These include avoiding endonasal surgery for olfactory groove meningiomas that approach the back wall of the frontal sinus, where closure is challenging, and avoiding those patients with preserved smell in whom surgery from above might be able to preserve a working olfactory nerve. For those patients we prefer to use an endoscope-assisted, supraciliary "eyebrow" incision. Likewise, we do not offer endonasal surgery to patients with petroclival meningiomas if the dural attachment of the tumor extends beyond the medial wall of the extradural vertical internal carotid artery. In these circumstances a combined above and below approach may be indicated. ${ }^{17}$ Likewise, the aim of GTR should not be the goal in all meningiomas in the skull base. ${ }^{4,13}$ In some instances, an STR followed by radiosurgery is adequate, such as in elderly or infirm patients who may not tolerate a risky surgery or in those with cavernous sinus invasion.

Although the complication rate in this series appears high, we included even more minor transient complications such as deep venous thrombosis, sinusitis, and transient DI. We included these more minor complications to fully explore the role of the cortical cuff and brain edema in surgical outcomes. In general, we found that the cortical cuff and brain edema were not significant because almost all meningioma surgeries require the surgeon to be able to dissect the capsule of the tumor off the surrounding vessels and pia or invaded brain, and these skills can be acquired by an experienced endonasal surgeon. Moreover, the most feared complication (postoperative CSF leak) is not affected at all by the absence of a cortical cuff or presence of brain edema. In fact, only improvements in technical skill and new closure techniques play a role in this outcome metric. While earlier groups reported rates of CSF leak as high as $32 \%-40 \%$ for meningiomas, ${ }^{19,49}$ we reported an overall rate of only $14.3 \%$, and that rate has dropped to $0 \%$ over the last 6 years. The relatively low number of complications for endonasal surgery compared with transcranial surgery for meningiomas is supported by studies of de Deviitis et al. ${ }^{12}$ and Kitano et al., ${ }^{31}$ which showed that non-CSF leak complications were lower in the endonasal group. In agreement with our recent data, other series of endonasal meningioma surgeries have also been able to achieve a 0\% CSF leak rate in smaller series of patients. ${ }^{7,49}$

\section{Conclusions}

In this study we demonstrate that the most important factor in successful endonasal meningioma surgery is surgical experience, not only as it is related to technical skill, but also to case selection. This factor far outweighs other radiological criteria such as the presence of a cortical cuff or brain edema. Surgeons endeavoring to perform endonasal meningioma surgery should be well versed in bimanual microdissection and multilayer closure techniques prior to embarking on these challenging cases.

\section{Disclosure}

Dr. Schwartz has direct stock ownership in Visionsense, has served as a consultant to Karl Storz, and has received support for non-study-related clinical or research effort from the NIH. Some of the cases in this paper have been presented in prior publications.

Author contributions to the study and manuscript preparation include the following. Conception and design: Schwartz. Acquisition of data: Khan. Analysis and interpretation of data: Schwartz, Khan. Drafting the article: Khan. Critically revising the article: Schwartz, Anand. Reviewed submitted version of manuscript: Schwartz. 
Approved the final version of the manuscript on behalf of all authors: Schwartz. Statistical analysis: Khan. Study supervision: Schwartz.

\section{References}

1. Ammirati M, Bernardo A: Analytical evaluation of complex anterior approaches to the cranial base: an anatomic study. Neurosurgery 43:1398-1408, 1998

2. Attia M, Kandasamy J, Jakimovski D, Bedrosian J, Alimi M, Lee DL, et al: The importance and timing of optic canal exploration and decompression during endoscopic endonasal resection of tuberculum sella and planum sphenoidale meningiomas. Neurosurgery 71 (1 Suppl Operative):58-67, 2012

3. Attia M, Umansky F, Paldor I, Dotan S, Shoshan Y, Spektor S: Giant anterior clinoidal meningiomas: surgical technique and outcomes. Clinical article. J Neurosurg 117:654-665, 2012

4. Bowers CA, Altay T, Couldwell WT: Surgical decision-making strategies in tuberculum sellae meningioma resection. Neurosurg Focus 30(5):E1, 2011

5. Cappabianca P, Cavallo LM, Esposito F, De Divitiis E: Editorial. Craniopharyngiomas. J Neurosurg 109:1-5, 2008

6. Ceylan S, Koc K, Anik I: Endoscopic endonasal transsphenoidal approach for pituitary adenomas invading the cavernous sinus. J Neurosurg 112:99-107, 2010 (Erratum in J Neurosurg 112:210, 2010)

7. Ceylan S, Koc K, Anık I: Extended endoscopic transphenoidal approach for tuberculum sellae meningiomas. Acta Neurochir (Wien) 153:1-9, 2011

8. Coppens J, Couldwell W: Olfactory groove meningiomas, in Pamir MN, Black PM, Fahlbusch R (eds): Meningiomas: A Comprehensive Text. Philadelphia: Saunders, 2010, p 373386

9. Couldwell WT, Rosenow JM, Rovit RL, Benzil DL: Hypophysopexy technique for radiosurgical treatment of cavernous sinus pituitary adenoma. Pituitary 5:169-173, 2002

10. Couldwell WT, Weiss MH, Rabb C, Liu JK, Apfelbaum RI, Fukushima T: Variations on the standard transsphenoidal approach to the sellar region, with emphasis on the extended approaches and parasellar approaches: surgical experience in 105 cases. Neurosurgery 55:539-550, 2004

11. de Divitiis E, Cavallo LM, Esposito F, Stella L, Messina A: Extended endoscopic transsphenoidal approach for tuberculum sellae meningiomas. Neurosurgery 62 (6 Suppl 3):11921201,2008

12. de Divitiis E, Esposito F, Cappabianca P, Cavallo LM, de Divitiis O: Tuberculum sellae meningiomas: high route or low route? A series of 51 consecutive cases. Neurosurgery 62: $556-563,2008$

13. Dehdashti AR, Ganna A, Witterick I, Gentili F: Expanded endoscopic endonasal approach for anterior cranial base and suprasellar lesions: indications and limitations. Neurosurgery 64:677-689, 2009

14. DeMonte F: Surgical treatment of anterior basal meningiomas. J Neurooncol 29:239-248, 1996

15. Fatemi N, Dusick JR, de Paiva Neto MA, Malkasian D, Kelly DF: Endonasal versus supraorbital keyhole removal of craniopharyngiomas and tuberculum sellae meningiomas. Neurosurgery 64 (5 Suppl 2):269-286, 2009

16. Fernandez-Miranda JC, Gardner PA, Snyderman CH: Endoscopic endonasal approach for tuberculum sellae meningiomas. Neurosurgery 69:E260-E261, 2011

17. Ganna A, Dehdashti AR, Karabatsou K, Gentili F: Fronto-basal interhemispheric approach for tuberculum sellae meningiomas; long-term visual outcome. Br J Neurosurg 23:422-430, 2009

18. Garcia-Navarro V, Anand VK, Schwartz TH: Gasket seal closure for extended endonasal endoscopic skull base surgery: efficacy in a large case series. World Neurosurg 80:563-568, 2013

19. Gardner PA, Kassam AB, Thomas A, Snyderman CH, Car- rau RL, Mintz AH, et al: Endoscopic endonasal resection of anterior cranial base meningiomas. Neurosurgery 63:36-54, 2008

20. Greenfield JP, Anand VK, Kacker A, Seibert MJ, Singh A, Brown SM, et al: Endoscopic endonasal transethmoidal transcribriform transfovea ethmoidalis approach to the anterior cranial fossa and skull base. Neurosurgery 66:883-892, 2010

21. Hadad G, Bassagasteguy L, Carrau RL, Mataza JC, Kassam A, Snyderman $\mathrm{CH}$, et al: A novel reconstructive technique after endoscopic expanded endonasal approaches: vascular pedicle nasoseptal flap. Laryngoscope 116:1882-1886, 2006

22. Hentschel SJ, DeMonte F: Olfactory groove meningiomas. Neurosurg Focus 14(6):E4, 2003

23. Jakimovski D, Bonci G, Attia M, Shao H, Hofstetter C, Tsiouris $\mathrm{AJ}$, et al: Incidence and significance of intraoperative cerebrospinal fluid leak in endoscopic pituitary surgery using intrathecal fluorescein. World Neurosurg [epub ahead of print], 2013

24. Jho HD, Alfieri A: Endoscopic glabellar approach to the anterior skull base: a technical note. Minim Invasive Neurosurg 45:185-188, 2002

25. Kaptain GJ, Vincent DA, Sheehan JP, Laws ER Jr: Transsphenoidal approaches for the extracapsular resection of midline suprasellar and anterior cranial base lesions. Neurosurgery 49:94-101, 2001

26. Kassam AB, Prevedello DM, Carrau RL, Snyderman CH, Thomas A, Gardner P, et al: Endoscopic endonasal skull base surgery: analysis of complications in the authors' initial 800 patients. A review. J Neurosurg 114:1544-1568, 2011

27. Ketcham AS, Hoye RC, Van Buren JM, Johnson RH, Smith RR: Complications of intracranial facial resection for tumors of the paranasal sinuses. Am J Surg 112:591-596, 1966

28. Ketcham AS, Wilkins RH, Vanburen JM, Smith RR: A combined intracranial facial approach to the paranasal sinuses. Am J Surg 106:698-703, 1963

29. Khan OH, Krischek B, Holliman D, Klironomos G, Kucharczyk W, Vescan A, et al: Pure endoscopic expanded endonasal approach for olfactory groove and tuberculum sellae meningiomas. J Clin Neurosci 21:927-933, 2014

30. Kitano M, Taneda M: Extended transsphenoidal approach with submucosal posterior ethmoidectomy for parasellar tumors. Technical note. J Neurosurg 94:999-1004, 2001

31. Kitano M, Taneda M, Nakao Y: Postoperative improvement in visual function in patients with tuberculum sellae meningiomas: results of the extended transsphenoidal and transcranial approaches. J Neurosurg 107:337-346, 2007

32. Kulwin C, Schwartz TH, Cohen-Gadol AA: Endoscopic extended transsphenoidal resection of tuberculum sellae meningiomas: nuances of neurosurgical technique. Neurosurg Focus 35(6): E6, 2013

33. Laufer I, Anand VK, Schwartz TH: Endoscopic, endonasal extended transsphenoidal, transplanum transtuberculum approach for resection of suprasellar lesions. J Neurosurg 106: 400-406, 2007

34. Lee JH, Sade B, Park BJ: A surgical technique for the removal of clinoidal meningiomas. Neurosurgery 59 (1 Suppl 1): ONS108-ONS114, 2006

35. Leng LZ, Brown S, Anand VK, Schwartz TH: "Gasket-seal" watertight closure in minimal-access endoscopic cranial base surgery. Neurosurgery 62 (5 Suppl 2):ONSE342-ONS343, 2008

36. Liu JK, Schmidt MH, MacDonald JD, Jensen RL, Couldwell WT: Hypophysial transposition (hypophysopexy) for radiosurgical treatment of pituitary tumors involving the cavernous sinus. Technical note. Neurosurg Focus 14(5):E11, 2003

37. Mascarenhas L, Moshel YA, Bayad F, Szentirmai O, Salek AA, Leng LZ, et al: The transplanum transtuberculum approaches for suprasellar and sellar-suprasellar lesions: avoidance of cerebrospinal fluid leak and lessons learned. World Neurosurg [epub ahead of print], 2013 


\section{O. H. Khan, V. K. Anand, and T. H. Schwartz}

38. Mason RB, Nieman LK, Doppman JL, Oldfield EH: Selective excision of adenomas originating in or extending into the pituitary stalk with preservation of pituitary function. J Neurosurg 87:343-351, 1997

39. McCoul ED, Anand VK, Singh A, Nyquist GG, Schaberg MR, Schwartz TH: Long-term effectiveness of a reconstructive protocol using the nasoseptal flap after endoscopic skull base surgery. World Neurosurg 81:136-143, 2014

40. Nakamura M, Roser F, Struck M, Vorkapic P, Samii M: Tuberculum sellae meningiomas: clinical outcome considering different surgical approaches. Neurosurgery 59:1019-1029, 2006

41. Nyquist GG, Anand VK, Singh A, Schwartz TH: Janus flap: bilateral nasoseptal flaps for anterior skull base reconstruction. Otolaryngol Head Neck Surg 142:327-331, 2010

42. Ogawa Y, Tominaga T: Extended transsphenoidal approach for tuberculum sellae meningioma-what are the optimum and critical indications? Acta Neurochir (Wien) 154:621-626, 2012

43. Ottenhausen M, Banu MA, Placantonakis DG, Tsiouris AJ, $\mathrm{Khan} \mathrm{OH}$, Anand VK, et al: Endoscopic endonasal resection of suprasellar meningiomas: the importance of case selection and experience in determining extent of resection, visual improvement and complications. World Neurosurg [epub ahead of print], 2014

44. Placantonakis DG, Tabaee A, Anand VK, Hiltzik D, Schwartz TH: Safety of low-dose intrathecal fluorescein in endoscopic cranial base surgery. Neurosurgery 61 (3 Suppl):161-166, 2007

45. Schwartz TH, Fraser JF, Brown S, Tabaee A, Kacker A, Anand VK: Endoscopic cranial base surgery: classification of operative approaches. Neurosurgery 62:991-1005, 2008

46. Sekhar LN, Nanda A, Sen CN, Snyderman CN, Janecka IP:
The extended frontal approach to tumors of the anterior, middle, and posterior skull base. J Neurosurg 76:198-206, 1992

47. Tabaee A, Placantonakis DG, Schwartz TH, Anand VK: Intrathecal fluorescein in endoscopic skull base surgery. Otolaryngol Head Neck Surg 137:316-320, 2007

48. Taussky P, Kalra R, Coppens J, Mohebali J, Jensen R, Couldwell WT: Endocrinological outcome after pituitary transposition (hypophysopexy) and adjuvant radiotherapy for tumors involving the cavernous sinus. Clinical article. J Neurosurg 115:55-62, 2011

49. Van Gompel JJ, Frank G, Pasquini E, Zoli M, Hoover J, Lanzino G: Expanded endonasal endoscopic resection of anterior fossa meningiomas: report of 13 cases and meta-analysis of the literature. Neurosurg Focus 30(5):E15, 2011

50. Weiss MH: The transnasal transsphenoidal approach, in Apuzzo MLJ (ed): Surgery of the Third Ventricle. Baltimore: Williams \& Wilkins, 1987, pp 476-494

51. Yaşargil M: Microneurosurgery: Operative Treatment of CNS Tumors. Stuttgart: Thieme, 1995, Vol 4B

52. Zada G, Du R, Laws ER Jr: Defining the "edge of the envelope": patient selection in treating complex sellar-based neoplasms via transsphenoidal versus open craniotomy. Clinical article. J Neurosurg 114:286-300, 2011

Manuscript submitted June 15, 2014.

Accepted July 9, 2014.

Please include this information when citing this paper: DOI: 10.3171/2014.7.FOCUS14321.

Address correspondence to: Theodore H. Schwartz, M.D., Department of Neurosurgery, Weill Cornell Medical College, New York Presbyterian Hospital, 525 E. 68th St., Box 99, New York, NY 10065.email: schwarh@med.cornell.edu. 